\title{
Strong Convergence Results for Fixed Point Iterations in Convex Metric Spaces
}

\author{
Ashish \\ Department of Mathematics, \\ Maharshi Dayanand University, Rohtak- \\ 124001(INDIA)
}

\author{
Preety \\ Department of Mathematics, \\ Maharshi Dayanand University, Rohtak- \\ 124001(INDIA)
}

\begin{abstract}
In this paper, we prove strong convergence results for some Jungck type iterative schemes in Convex metric spaces for a pair of non-selfmappings using a certain contractive condition. Our results generalize existing results in the literature.
\end{abstract}

\section{Keywords}

Jungck-iterative schemes, fixed point, contractive conditions, Convex metric spaces.

\section{INTRODUCTION AND \\ PRELIMINARIES}

In 1970, Takahashi [16] introducedthe notion of convex metric space and studied the fixed point theorems for nonexpansive mappings. He defined that a map $W: X^{2} \times[0,1] \rightarrow X$ is a convex structure in $\mathrm{X}$ if

$$
d(u, W(x, y, \lambda)) \leq \lambda d(u, x)+(1-\lambda) d(u, y)
$$

for all $x, y, u \in X$ and $\lambda \in[0,1]$. A metric space $(X, d)$ together with a convex structure $W$ is known as convex metric space and is denoted by $(X, d, W)$. A nonempty subset $C$ of a convex metric space is convex if $W(x, y, \lambda) \in C$ for all $x, y \in C$ and $\lambda \in[0,1]$.

Remark 1.1 Every normed space is a convex metric space, where a convex structure

$W(x, y, z ; \alpha, \beta, \gamma)=\alpha x+\beta y+\gamma z$, for all $x, y, z \in X$ and $\alpha, \beta, \gamma \in[0,1]$ with $\alpha+\beta+\gamma=1$. In fact,

$$
\begin{aligned}
d(u, W(x, y, z ; \alpha, \beta, \gamma)) & =\|u-(\alpha x+\beta y+\gamma z)\| \\
\leq & \alpha\|u-x\|+\beta\|u-y\|+\gamma\|u-z\| \\
= & \alpha d(u, x)+\beta d(u, y)+\gamma d(u, z),
\end{aligned}
$$

for all $u \in X$. But there exists some convex metric spaces which cannot be embedded into normed spaces.

Let $\mathrm{X}$ be a Banach space, $\mathrm{Y}$ an arbitrary set, and $S, T: Y \rightarrow X$ such that $T(\mathrm{Y}) \subseteq \mathrm{S}(\mathrm{Y})$. For $x_{0} \in Y$, consider the following iterative scheme:

$$
S x_{n+1}=T x_{n}, n=0,1,2 \ldots
$$

is called Jungck iterative scheme and was essentially introduced by Jungck [1] in 1976 and it becomes the Picard iterative scheme when $S=I_{d}$ (identity mapping) and $Y=X$.

$\alpha_{n} \in[0,1]$, Singh et al. [2] defined the Jungck-Mann iterative scheme as

$$
S x_{n+1}=\left(1-\alpha_{n}\right) \mathrm{S} x_{n}+\alpha_{n} T x_{n}, n=0,1,2 \ldots .
$$

For $\alpha_{n}, \beta_{n}, \gamma_{n} \in[0,1]$, Olatinwo defined the Jungck Ishikawa [3] (see also [4, 5]) and Jungck-Noor [6] iterative schemes as

$$
\begin{aligned}
& S x_{n+1}=\left(1-\alpha_{n}\right) \mathrm{S} x_{n}+\alpha_{n} T y_{n}, \\
& S y_{n}=\left(1-\beta_{n}\right) \mathrm{S} x_{n}+\beta_{n} T x_{n}, n=0,1,2 \ldots \\
& S x_{n+1}=\left(1-\alpha_{n}\right) \mathrm{S} x_{n}+\alpha_{n} T y_{n}, \\
& S y_{n}=\left(1-\beta_{n}\right) \mathrm{S} x_{n}+\beta_{n} T z_{n}, \\
& S z_{n}=\left(1-\gamma_{n}\right) \mathrm{S} x_{n}+\gamma_{n} T x_{n}, n=0,1,2 \ldots .
\end{aligned}
$$

respectively.

Chugh and Kumar [7] defined the Jungck-SP iterative scheme as

$$
\begin{aligned}
& S x_{n+1}=\left(1-\alpha_{n}\right) \mathrm{S} y_{n}+\alpha_{n} T y_{n}, \\
& S y_{n}=\left(1-\beta_{n}\right) \mathrm{S} z_{n}+\beta_{n} T z_{n}, \\
& S z_{n}=\left(1-\gamma_{n}\right) \mathrm{S} x_{n}+\gamma_{n} T x_{n}, n=0,1,2 \ldots .
\end{aligned}
$$

where $\left\{\alpha_{n}\right\}_{n=0}^{\infty},\left\{\beta_{n}\right\}_{n=0}^{\infty}$ and $\left\{\gamma_{n}\right\}_{n=0}^{\infty}$ are sequences in $[0,1]$.

Remark 1.2 If $X=Y$ and $S=I_{d}$ (identity mapping), then the Jungck-SP (1.5), Jungck-Noor (1.4), Jungck-Ishikawa (1.3), and the Jungck-Mann (1.2) iterative schemes, respectively, become the SP [8], Noor [9], Ishikawa [10] and the Mann [11] iterative schemes.

Jungck [1] used the iterative scheme (1.1) to approximate the common fixed points of the mappings $S$ and $T$ satisfying the following Jungck contraction:

$$
d(T x, T y) \leq(S x, S y), 0 \leq \alpha<1 .
$$

Olatinwo [3] used the following more general contractive definition than (1.6) to prove the stability and strong convergence results for the Jungck-Ishikawa iteration process: there exists a real number $a \in[0,1)$ and a monotone increasing function $\varphi: R^{+} \rightarrow R^{+}$such that $\varphi(0)=0$ and for all $\quad x, y \in Y$, we have

$$
d(T x, T y) \leq \varphi d(S x, T x)+a d(S x, S y) .
$$

Olatinwo [6] used the convergences of Jungck-Noor iterative scheme (1.4) to approximate the coincidence points (not common fixed points) of some pairs of generalized contractive like operators with the assumption that one of each of the pairs of maps is injective. 
Motivated by the above facts, for $\alpha_{n}, \beta_{n}, \gamma_{n} \in[0,1]$, Chugh et. al.[17] introduce the following iterative scheme:

$$
\begin{aligned}
& S x_{n+1}=\left(1-\alpha_{n}\right) \mathrm{S} y_{n}+\alpha_{n} T y_{n}, \\
& S y_{n}=\left(1-\beta_{n}\right) T x_{n}+\beta_{n} T z_{n}, \\
& S z_{n}=\left(1-\gamma_{n}\right) \mathrm{S} x_{n}+\gamma_{n} T x_{n}, n=0,1,2 \ldots .
\end{aligned}
$$

and called it Jungck-CR iterative scheme.

Remark 1.3. Putting

$$
\alpha_{n}=0 \text { and } \alpha_{n}=0, \beta_{n}=1
$$

in Jungck-CR iterative scheme, we get Jungck versions of Agarwal et al. [12] and Sahu and Petrus, el [13] iterative schemes, respectively, as

defined below:

$S x_{n+1}=\left(1-\beta_{n}\right) \mathrm{Tx}_{n}+\beta_{n} T y_{n}$,

$S y_{n}=\left(1-\gamma_{n}\right) \mathrm{S} x_{n}+\gamma_{n} T x_{n}$

and

$S x_{n+1}=T y_{n}$,

$S y_{n}=\left(1-\gamma_{n}\right) \mathrm{S} x_{n}+\gamma_{n} T x_{n}$,

Now we give the above iterative schemes in the setting of convex metric spaces:

Let $(\mathrm{X}, \mathrm{d}, \mathrm{W})$ be a convex metric spaces. For $x_{0} \in X$, we have

(1.1.1) Jungck Picard iterative scheme:

$$
S x_{n+1}=T x_{n}, n=0,1,2 \ldots
$$

(1.1.2) Jungck Mann iterative scheme:

$$
S x_{n+1}=W\left(\mathrm{~S} x_{n}, T x_{n}, \alpha_{n}\right), n=0,1,2 \ldots
$$

where $\left\{\alpha_{n}\right\}_{n=0}^{\infty}$ is a real sequence in $[0,1]$.

(1.1.3) Jungck Ishikawa iterative scheme:

$$
\begin{aligned}
& S x_{n+1}=W\left(\mathrm{~S} x_{n}, T y_{n}, \alpha_{n}\right) \\
& S y_{n}=W\left(\mathrm{~S} x_{n}, T x_{n}, \beta_{n}\right), n=0,1,2 \ldots
\end{aligned}
$$

where $\left\{\alpha_{n}\right\}_{n=0}^{\infty}$ and $\left\{\beta_{n}\right\}_{n=0}^{\infty}$ are real sequences in $[0,1]$.

(1.1.4) Jungck Noor iterative scheme:

$$
\begin{aligned}
& S x_{n+1}=W\left(\mathrm{~S} x_{n}, T y_{n}, \alpha_{n}\right) \\
& S y_{n}=W\left(\mathrm{~S} x_{n}, T z_{n}, \beta_{n}\right) \\
& S z_{n}=W\left(\mathrm{~S} x_{n}, T x_{n}, \gamma_{n}\right), n=0,1,2 \ldots .
\end{aligned}
$$

where $\left\{\alpha_{n}\right\}_{n=0}^{\infty},\left\{\beta_{n}\right\}_{n=0}^{\infty}$ and $\left\{\gamma_{n}\right\}_{n=0}^{\infty}$ are real sequences in $[0,1]$.

(1.1.5) Jungck Agarrwal iterative scheme:

$$
\begin{aligned}
& S x_{n+1}=W\left(T x_{n}, T y_{n}, \alpha_{n}\right) \\
& S y_{n}=W\left(\mathrm{~S} x_{n}, T x_{n}, \beta_{n}\right), n=0,1,2 \ldots .
\end{aligned}
$$

where $\left\{\alpha_{n}\right\}_{n=0}^{\infty}$ and $\left\{\beta_{n}\right\}_{n=0}^{\infty}$ are sequences of positive numbers in $[0,1]$.

(1.1.6) Jungck SP-iterative scheme:

$$
\begin{aligned}
& S x_{n+1}=W\left(\mathrm{~S} y_{n}, T y_{n}, \alpha_{n}\right), \\
& S y_{n}=W\left(\mathrm{~S} z_{n}, T z_{n}, \beta_{n}\right), \\
& S z_{n}=W\left(\mathrm{~S} x_{n}, T x_{n}, \gamma_{n}\right), n=0,1,2 \ldots .
\end{aligned}
$$

(1.1.7) Jungck CR-iterative scheme:

$$
\begin{aligned}
& S x_{n+1}=W\left(\mathrm{~S} y_{n}, T y_{n}, \alpha_{n}\right), \\
& S y_{n}=W\left(T x_{n}, T z_{n}, \beta_{n}\right), \\
& S z_{n}=W\left(\mathrm{~S} x_{n}, T x_{n}, \gamma_{n}\right), n=0,1,2 \ldots . .
\end{aligned}
$$

Where $\left\{\alpha_{n}\right\}_{n=0}^{\infty},\left\{\beta_{n}\right\}_{n=0}^{\infty}$ and $\left\{\gamma_{n}\right\}_{n=0}^{\infty}$ are sequences in $[0,1]$.

We will need the following definition to prove our main result:

Definition 1.4 (see $[14,15])$. Let $f$ and $g$ be two self-maps on $X$. A point $x$ in $X$ is called (1) a fixed point of $f$ if $(x)=x$; (2) coincidence point of a pair $(f, g)$ if $f x=g x$; (3) common fixed point of a pair $(f, g)$ if $x=f x=g x$. If $w=f x=g x$ for some $x$ in $X$, then $w$ is called a point of coincidence of $f$ and $g$. A pair $(f, g)$ is said to be weakly compatible if $f$ and $g$ commute at their coincidence points.

Now we will give our main results:

\section{CONVERGENCE RESULTS}

Theorem 2.1. Let $(\mathrm{X}, \mathrm{d}, \mathrm{W})$ be an arbitrary Convex metric space and let $S, T: Y \rightarrow X$ be nonself -operators on an arbitrary set $Y$ satisfying contractive condition (1.7). Assume that $T(\mathrm{Y}) \subseteq \mathrm{S}(\mathrm{Y}), \quad S(\mathrm{Y})$ is a complete subspace of $X$ and $S z=T z=p$ (say). For $x_{0} \in Y$, let $\left\{\mathrm{Sx}_{n}\right\}_{n=0}^{\infty}$ be the Jungck CR iteration defined by (1.1.7), where $\left\{\alpha_{n}\right\},\left\{\beta_{n}\right\},\left\{\gamma_{n}\right\}$ are sequences of positive numbers in $[0,1]$ with $\left\{\alpha_{n}\right\}$ satisfying $\sum_{n=0}^{\infty} \alpha_{n}=\infty$. Then, the Jungck-CR iterative process $\left\{\mathrm{Sx}_{n}\right\}_{n=0}^{\infty}$ converges strongly to $p$. Also, $\mathrm{p}$ will be the unique common fixed point of $\mathrm{S}, \mathrm{T}$ provided that $\mathrm{Y}=\mathrm{X}$, and $\mathrm{S}$ and $\mathrm{T}$ are weakly compatible.

Proof. First, we prove that $p$ is the unique common fixed point of $S$ and $T$. Let there exist another point of coincidence say $\mathrm{p}^{*}$. Then, there exists $q^{*} \in X$ such that $S q^{*}=T q^{*}=p^{*}$. But from (1.7), we have

$$
\begin{aligned}
0 \leq d\left(\mathrm{p}, \mathrm{p}^{*}\right) & =\mathrm{d}\left(\mathrm{Tq}, \mathrm{Tq}^{*}\right) \\
& \leq \varphi d(\mathrm{Sq}, \mathrm{Tq})+\operatorname{ad}\left(\mathrm{Sq}, \mathrm{Sq}^{*}\right) \\
& =\operatorname{ad}\left(\mathrm{p}, \mathrm{p}^{*}\right)
\end{aligned}
$$

which implies that $p=p^{*}$ as $0 \leq a<1$.

Now, as $\mathrm{S}$ and $\mathrm{T}$ are weakly compatible and $\mathrm{p}=\mathrm{Tq}=\mathrm{Sq}$, so $\mathrm{Tp}$ $=\mathrm{TTq}=\mathrm{TSq}=\mathrm{STq}$ and hence $\mathrm{Tp}=\mathrm{Sp}$. Therefore, $\mathrm{Tp}$ is a point of coincidence of $S, T$ and since the point of coincidence is unique then $\mathrm{p}=\mathrm{Tp}$. Thus, $\mathrm{Tp}=\mathrm{Sp}=\mathrm{p}$, and therefore $\mathrm{p}$ is unique common fixed point of $\mathrm{S}$ and $\mathrm{T}$. 
Now we prove that Jungck-CR iterative process $\left\{\mathrm{Sx}_{n}\right\}_{n=0}^{\infty}$ converges strongly to $p$.

Using (1.1.7) and condition (1.7), we have

$$
\begin{aligned}
& d\left(\mathrm{Sx}_{n+1}, \mathrm{p}\right)= \mathrm{d}\left(\mathrm{W}\left(\mathrm{Sy}_{n}, \mathrm{Ty}_{n}, \alpha_{n}\right), \mathrm{p}\right) \\
& \leq\left(1-\alpha_{n}\right) \mathrm{d}\left(\mathrm{Sy}_{n}, \mathrm{p}\right)+\alpha_{n} d\left(\mathrm{Ty}_{n}, \mathrm{p}\right) \\
&=\left(1-\alpha_{n}\right) \mathrm{d}\left(\mathrm{Sy}_{n}, \mathrm{p}\right)+\alpha_{n} d\left(\mathrm{Tz} \mathrm{Ty}_{n}\right) \\
& \leq\left(1-\alpha_{n}\right) \mathrm{d}\left(\mathrm{Sy}_{n}, \mathrm{p}\right)+\alpha_{n}\left\{\varphi d(\mathrm{Sz}, \mathrm{Tz})+\mathrm{a} d\left(\mathrm{Sz} \mathrm{Sy}_{n}\right)\right\} \\
&=\left(1-\alpha_{n}\right) \mathrm{d}\left(\mathrm{Sy}_{n}, \mathrm{p}\right)+\alpha_{n} a d\left(\mathrm{Sy}_{n}, \mathrm{p}\right) \\
&=\left[1-\alpha_{n}(1-\mathrm{a})\right] \mathrm{d}\left(\mathrm{Sy}_{n}, \mathrm{p}\right) .
\end{aligned}
$$

For $d\left(\mathrm{Sy}_{n}, \mathrm{p}\right)$, we have

$$
\begin{aligned}
& d\left(\mathrm{Sy}_{n}, \mathrm{p}\right)= \mathrm{d}\left(\mathrm{W}\left(\mathrm{Tx}_{n}, \mathrm{Tz}_{n}, \beta_{n}\right), \mathrm{p}\right) \\
& \leq\left(1-\beta_{n}\right) \mathrm{d}\left(\mathrm{Tx}_{n}, \mathrm{p}\right)+\beta_{n} d\left(\mathrm{Tz}_{n}, \mathrm{p}\right) \\
& \leq\left(1-\beta_{n}\right) \mathrm{d}\left(\mathrm{Tx}_{n}, \mathrm{Tz}\right)+\beta_{n} d\left(\mathrm{Tz}_{n}, \mathrm{Tz}\right) \\
& \leq\left(1-\beta_{n}\right)\left(\varphi d(\mathrm{Sz}, \mathrm{Tz})+\mathrm{ad}\left(\mathrm{Sx}_{n}, \mathrm{Sz}\right)\right)+ \\
& \beta_{n}\left\{\varphi d(\mathrm{Sz}, \mathrm{Tz})+a d\left(\mathrm{Sz}_{n}, \mathrm{Sz}\right)\right\} \\
& \leq\left(1-\beta_{n}\right) \mathrm{ad}\left(\mathrm{Sx}_{n}, \mathrm{p}\right)+\beta_{n} a d\left(\mathrm{Sz}_{n}, \mathrm{p}\right), \\
& d\left(\mathrm{Sz}_{n}, \mathrm{p}\right)= \mathrm{d}\left(\mathrm{W}\left(\mathrm{Sx}_{n}, \mathrm{Tx}_{n}, \gamma_{n}\right), \mathrm{p}\right) \\
& \leq\left(1-\gamma_{n}\right) \mathrm{d}\left(\mathrm{Sx}_{n}, \mathrm{p}\right)+\gamma_{n} d\left(\mathrm{Tx}_{n}, \mathrm{p}\right) \\
& \leq\left(1-\gamma_{n}\right) \mathrm{d}\left(\mathrm{Sx}_{n}, \mathrm{p}\right)+\gamma_{n} d\left(\mathrm{Tx}_{n}, \mathrm{Tz}\right) \\
& \leq\left(1-\gamma_{n}\right) \mathrm{d}\left(\mathrm{Sx}_{n}, \mathrm{p}\right)+\gamma_{n}\left\{\varphi d\left(\mathrm{Sz}_{1}, \mathrm{Tz}\right)+\mathrm{ad}\left(\mathrm{Sx}_{n}, \mathrm{Sz}\right)\right\} \\
& \quad=\left(1-\gamma_{n}(1-\mathrm{a})\right) \mathrm{d}\left(\mathrm{Sx}_{n}, \mathrm{p}\right) .
\end{aligned}
$$

It follows from (2.1.3) that

$$
d\left(\mathrm{Sy}_{n}, \mathrm{p}\right) \leq\left(1-\beta_{n}\right) \operatorname{ad}\left(\mathrm{Sx}_{n}, \mathrm{p}\right)+\beta_{n} a\left(1-\gamma_{n}(1-\mathrm{a})\right) \mathrm{d}\left(\mathrm{Sx}_{n}, \mathrm{p}\right) .
$$

Using $\left(1-\beta_{n}\right) \mathrm{a} \leq\left(1-\beta_{n}\right)$ and $\beta_{n} a\left(1-\gamma_{n}(1-\mathrm{a})\right) \leq \beta_{n} a$,

inequality (2.1.4) yields

$$
d\left(\mathrm{Sy}_{n}, \mathrm{p}\right) \leq\left(1-\beta_{n}(1-\mathrm{a})\right) \mathrm{d}\left(\mathrm{Sx}_{n}, \mathrm{p}\right)
$$

From (2.1.5) and (2.1.1), we get

$$
\begin{aligned}
d\left(\mathrm{Sx}_{n+1}, \mathrm{p}\right) & \leq\left[1-\alpha_{n}(1-\mathrm{a})\right]\left[1-\beta_{n}(1-\mathrm{a})\right] \mathrm{d}\left(\mathrm{Sx}_{n}, \mathrm{p}\right) \\
& \leq\left[1-\alpha_{n}(1-\mathrm{a})\right] \mathrm{d}\left(\mathrm{Sx}_{n}, \mathrm{p}\right) \\
& \leq \prod_{k=0}^{n}\left[1-(1-a) \alpha_{k}\right] \mathrm{d}\left(\mathrm{Sx}_{0}, \mathrm{p}\right) \\
& \leq \mathrm{e}^{-(1-\mathrm{a}) \sum_{k=0}^{\infty} \alpha_{k}} \mathrm{~d}\left(\mathrm{Sx}_{0}, \mathrm{p}\right) .
\end{aligned}
$$

Since $\quad \alpha_{k} \in[0,1], 0 \leq \mathrm{a}<1$ and $\quad \sum_{n=0}^{\infty} \alpha_{n}=\infty, \quad$ so $e^{-(1-\mathrm{a}) \sum_{k=0}^{n} \alpha_{k}} d\left(\mathrm{Sx}_{0}, \mathrm{p}\right) \rightarrow 0$ as $\mathrm{n} \rightarrow \infty$.
Hence from equation (2.1.6) we get, $d\left(\mathrm{Sx}_{n+1}, \mathrm{p}\right) \rightarrow 0$ as $\mathrm{n} \rightarrow \infty, \quad$ that $\quad$ is $\quad\left\{\mathrm{Sx}_{n}\right\}_{n=0}^{\infty}$ converges strongly to $p$.

Corollary 2.2. Let $(\mathrm{X}, \mathrm{d}, \mathrm{W})$ be an arbitrary Convex metric space and let $S, T: Y \rightarrow X$ be nonself -operators on an arbitrary set $Y$ satisfying contractive condition (1.7). Assume that $T(\mathrm{Y}) \subseteq \mathrm{S}(\mathrm{Y}), \quad S(\mathrm{Y})$ is a complete subspace of $X$ and $S z=T z=p \quad$ (say). For $x_{0} \in Y$, let $\left\{\mathrm{Sx}_{n}\right\}_{n=0}^{\infty}$ be the iteration defined by (1.1.5), where $\left\{\alpha_{n}\right\},\left\{\beta_{n}\right\},\left\{\gamma_{n}\right\}$ are sequences of positive numbers in $[0,1]$ with $\left\{\alpha_{n}\right\}$ satisfying $\sum_{n=0}^{\infty} \alpha_{n}=\infty$. Then, the iterative process $\left\{\mathrm{Sx}_{n}\right\}_{n=0}^{\infty}$ converges strongly to $p$. Also, $\mathrm{p}$ will be the unique common fixed point of $\mathrm{S}, \mathrm{T}$ provided that $\mathrm{Y}=\mathrm{X}$, and $\mathrm{S}$ and $\mathrm{T}$ are weakly compatible.

Proof: Putting $\alpha_{n}=0$ and $\beta_{n}=\alpha_{n}$, in iterative scheme (1.1.7), convergence of iterative scheme (1.1.5) can be proved on the same lines as in Theorem 2.1.

Corollary 2.3. Let $(\mathrm{X}, \mathrm{d}, \mathrm{W})$ be an arbitrary Convex metric space and let $S, T: Y \rightarrow X$ be nonself -operators on an arbitrary set $Y$ satisfying contractive condition (1.7). Assume that $T(\mathrm{Y}) \subseteq \mathrm{S}(\mathrm{Y}), \quad S(\mathrm{Y})$ is a complete subspace of $X$ and $S z=T z=p$ (say). For $x_{0} \in Y$, let $\left\{\mathrm{Sx}_{n}\right\}_{n=0}^{\infty}$ be the Jungck-S iteration defined by (1.10), where $\left\{\alpha_{n}\right\},\left\{\beta_{n}\right\},\left\{\gamma_{n}\right\}$ are sequences of positive numbers in $[0,1]$ with $\left\{\alpha_{n}\right\}$ satisfying $\sum_{n=0}^{\infty} \alpha_{n}=\infty$. Then, the Jungck-S iterative process $\left\{\mathrm{Sx}_{n}\right\}_{n=0}^{\infty}$ converges strongly to $p$. Also, $\mathrm{p}$ will be the unique common fixed point of $\mathrm{S}, \mathrm{T}$ provided that $\mathrm{Y}=\mathrm{X}$, and $\mathrm{S}$ and $\mathrm{T}$ are weakly compatible.

Proof: Putting $\alpha_{n}=0$ and $\gamma_{n}=\alpha_{n}, \beta_{n}=1$, in iterative scheme (1.1.7), convergence of iterative scheme (1.10) can be proved on the same lines as in Theorem 2.1.

\section{REFERENCES}

[1] Jungck, G. 1976. Commuting mappings and fixed points. The American Mathematical Monthly. 83 (1976), 261-263.

[2] Singh, S. L., Bhatnagar, C. and Mishra S.N. 2005. Stability of Jungck type iterative procedures. International Journal of Mathematics and Mathematical Sciences. 19 (2005), 3035-3043.

[3] Olatinwo, M. O.Some stability and strong convergence results for the Jungck-Ishikawa iteration process. Creative Mathematics and Informatics. 17 (2008), 33-42.

[4] Bosede, A. O. 2010. Strong convergence results for the Jungck-Ishikawa and Jungck-Mann iteration processes. Bulletin of Mathematical Analysis and Applications. 2 (2010), 65-73.

[5] Olaleru, J. O. and Akewe, H. 2010. On multistep iterative scheme for approximating the common fixed points of contractive-like operators. International Journal of Mathematics and mathematical Sciences. 2010 (2010), Article ID 530964, 1-11. 
[6] Olatinwo, M. O. 2008. A generalization of some convergence results using a Jungck-Noor three-step iteration process in arbitrary Banach space, Polytechnica Posnaniensis. 40 (2008), 37-43.

[7] Chugh, R. and Kumar, V. 2011. Strong Convergence and Stability results for Jungck-SP iterative scheme. International Journal of Computer Applications. 36 (2011), 21-27.

[8] Phuengrattana, W. and Suantai, S. 2011. On the rate of convergence of Mann, Ishikawa, Noor and SP-iterations for continuous functions on an arbitrary interval. Journal of Computational and Applied Mathematics. 235 (2011), 3006-3014.

[9] Noor, M. A. 2000. New approximation schemes for general variational inequalities, Journal of Mathematical Analysis and Applications. 251 (2000), 217-229.

[10] Ishikawa, S. 1974. Fixed points by a new iteration method," Proceedings of the American Mathematical Society. 44 (1974), 147-150.

[11] Mann, W. R. 1953. Mean value methods in iteration. Proceedings of the American Mathematical Society. 4 (1953), 506-510.
[12] Agarwal, R. P., O’Regan, D. and Sahu, D. R. 2007. Iterative construction of fixed points of nearly asymptotically nonexpansive mappings. Journal of Nonlinear and Convex Analysis. 8 (2007), 61-79.

[13] Sahu, D. R. and Petrus, el, A. 2011. Strong convergence of iterative methods by strictly pseudocontractive mappings in Banach spaces. Nonlinear Analysis: Theory, Methods \& Applications. 74 (2011) 6012-6023.

[14] Hussain, N., Jungck, G. and Khamsi, M. A. 2012. Nonexpansive retracts and weak compatible pairs in metric spaces. Fixed Point Theory and Applications. 2012 (2012) article 100, 1-10.

[15] Jungck, G. and Hussain, N. 2007. Compatible maps and invariant approximations. Journal of Mathematical Analysis and Applications. 325 (2007) 1003-1012.

[16] Takahashi, W. 1970. A convexity in metric spaces and nonexpansive mapping. Kodai Math. Sem. Rep. 22 (1970), 142-149.

[17] Hussain, N., Kumar, V. and Kutbi, M. A. 2013. On rate of Convergence of Jungck type iterative schemes. Abstract and Applied Analysis. 2013 (2013), Article ID 132626, 15 pages. 